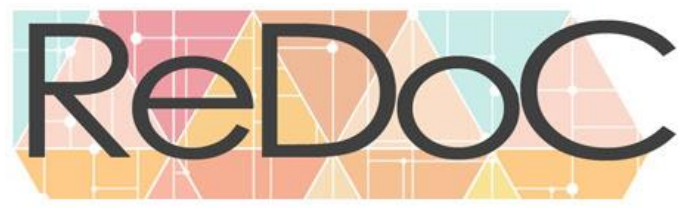

Revista Docência e Cibercultura

\title{
Densidades, devenires y nomadismos para restaurar una vieja e impermanente pedagogía: Una conversación con María Marta Yedaide $^{1}$
}

\section{Densities, Becomings and Nomadisms to Restore an Ancient and Impermanent Pedagogy. A Conversation with Maria Marta Yedaide}

Resumen: En esta conversación la pedagogía es presentada de una manera nómade y expandida, más que una disciplina su densidad deviene en narrativa. Desde la investigación educativa como una vocación política que desata y amarra pasados y presentes, esta entrevista biográfica reafirma una intención de indisciplinarla. El texto restaura condiciones que afectan y enredan nuestra condición humana, a la vez que convoca a autorizar otras narrativas para la educación más amables con nosotros mismos. De este modo el programa histórico de desafectación que promueve y sella la continuidad de nuestras instituciones sociales, es interrumpido parcialmente por la voz de esta pedagoga, en la que se reconocen prácticas de una pedagogía descolonial que trata de no moverse lejos de la vida y aspira a resistirse a la pulsión por los absolutos.

Palabras clave: Afectos, Giro descoloniales, Investigación narrativa, Pedagogía.

Abstract: In this conversation, pedagogy is presented in a nomadic and expanded sense; its density drifts away from the discipline and into the narrative domain. On the grounds of the conception of educational research as a political drive that both unleashes and tightens pasts and presents, this biographical interview reasserts the invite to indiscipline. The text recovers the conditions that affect and entangle our humanity, as it advocates for the authorization of alternative narratives in education which can be friendlier (more compassionate) to ourselves. In such a spirit, the historical scheme of disaffection that our social institutions promote and seal is somehow interrupted by this voice, rooted in decolonial practices that try to stay close to life and resist the compulsion for absolutes.

Keywords: Affections; Decolonial Turn; Narrative Research; Pedagogy

Submetido em: 04/06/2019 Aceito em: 06/08/2019 Publicado em: 31/08/2019.

${ }^{1}$ Directora, Docente e investigadora del Departamento de Ciencias de la Educación de la Facultad de Humanidades y Docente e investigadora del Departamento de Gestión Cultural de la Facultad de Arquitectura, Urbanismo y Diseño de la Universidad Nacional de Mar del Plata. Es Doctora en Humanidades y Artes (UNR), miembro del Grupo de Investigaciones en Educación y Estudios Culturales (GIEEC) y codirectora del Grupo de Investigación en Cultura, Educación Superior y Disciplinas Proyectuales (CESDIP). Correo electrónico: myedaide@ gmail.com

2 Docente e investigador del Departamento de Ciencias de la Educación de la Facultad de Humanidades (UNMdP) y Becario postdoctoral de CONICET. Doctor en Humanidades y Artes (UNR), es miembro del Grupo de Investigaciones en Educación y Estudios Culturales (GIEEC) y del Grupo de Investigación en Cultura, Educación Superior y Disciplinas Proyectuales (CESDIP). Correo electrónico: franarg@hotmail.com

\begin{tabular}{l|l|l|l|l|l|l} 
(C) Redoc & Rio de Janeiro & v. 3 & n.2 & p. 312 & Maio/Agosto 2019 & ISSN 2594-9004
\end{tabular}




\section{Revista Docência e Cibercultura}

\section{Breve aclaración}

En la redacción de este texto ocupa un lugar central la intensión de dislocar la (auto)arrogancia -explicadora e omnipresente- que caracteriza al saber científico objetivo, neutral o total. Es por eso que sus autores -entrevistada y entrevistadoroptaron por una conversación, que más allá de la presunta linealidad de una entrevista, aspira a habitar este género académico desde un diálogo cogenerado y entramado por experiencias vitales, aún más amplías que las aquí se nombran. Especialmente nos provocó el reciente libro de Tiago Ribero, Carmen Sanches y Rafael Ferreira (2018) en su interrogación sobre el estatus epistemológico, ontológico, político y pedagógico de la conversación como metodología y experiencia de investigación. Al tratarse de una metodología fuera de la metodología, que apuesta a escapar de la industria de la pesquisa y aventura otros modos de hacer investigación, este compartir de voces es una oportunidad para fugarse de la interpretación y de la autorización. $\mathrm{O}$ al menos a caminar también un poco a contrapelo de ellas, quizás por eso esta conversación deviene en una ocasión para pensar juntos.

\section{P1: María Marta para comenzar ¿podrías presentarte y contarnos cómo es tu relación con la pedagogía?}

Las cosas importantes para decir: estoy construida como mujer, como mamá y como pedagoga crítica y descolonial. Diría esto último como una intención o como un deseo, más que como algo que realmente exista. Para mí ser pedagoga tiene que ver con un sentido político, con una relación de vida y con una forma de expresar poder que se lleva puesto quien soy. No sé si hay una diferencia demasiado grande entre la pedagogía y mi identidad. Porque para mí la pedagogía tiene que ver con pensarme positivamente- en el sentido del poder positivo del mundo. Tiene que ver con aquello que yo hago, con algo que puede ser o que se puede hacer. Con no quedarme de brazos cruzados frente a lo que veo como dañino o injusto. Y que es injusto porque es creado por los hombres-ya que entiendo que hay una justicia esencial y final en todas las cosas que suceden. Además digo injusto porque existe mucho sufrimiento, un sufrimiento de los que quedan vulnerados en situaciones sociales en las que para mí amerita hacer algo. Una vez mi psicólogo me dijo que hay 49\% de cosas que están 
dispuestas en la vida de un tipo y $49 \%$ de otro, pero también hay un $1 \%$ que representa lo que uno puede hacer. Como el poema de Kabril Gibrán cuando habla de los hijos: "Tú eres el arco por el cual tus hijos, como flechas vivas son lanzados/ Deja que la inclinación en tu mano de arquero sea para la alegría", yo creo que lo que podemos hacer es una mínima inclinación en la mano de un arquero. Qué disperso lo que dije, ¿no? Lo que quiero decir es que es muy poquito lo que uno puede hacer y, a pesar de ello, es algo muy importante. Y creo que la educación, y que la pedagogía como su narrativa, es un lugar más que interesante para hacer esa inclinación. Nosotros podemos perfilar nuestra vida, y yo quisiera que mi vida quedara perfilada para el bienestar más que el sufrimiento.

También diría que para mí ser pedagoga es un proyecto vital, que no se puede separar de ser persona. ¿Qué quiero con la pedagogía? que haya más libertad y que se pueda respirar mejor. Que yo lo pueda hacer y que otros lo puedan hacer. Esta idea puede ser un poco desprolija porque es una idea en tránsito, que estoy fabricando casi cuando lo hablo con vos, muy movilizada por quien soy yo hoy en particular. Lo que valoro muchísimo es la libertad. A veces esa libertad es estar bailando en una baldosa y aún en esa baldosa, vos podés poner los pies para un lado o para el otro. Yo quiero que mi pie vaya para el bienestar, para la libertad y para la buena vida, quiero que se suceda algo de lo maravilloso. Y también quiero sentirme libre para que cuando no sucede pueda aceptar que no sucede. La pedagogía me ayuda a percibir espacios de libertad y me gustaría también que otros perciban espacios de libertad.

\section{P2: ¿Cómo caracterizarías tu biografía como pedagoga?}

R2: Mi identidad tiene una oportunidad de ser o de decirse en cada momento que hablo; no es que hay algo ya sabido. Y yo también me entero cuando hablo en qué punto de ese devenir me encuentro. Por eso pienso que las conversaciones y las charlas informales son oportunidades, y más aún con un par interesado y cuidadoso, alguien con quien no tengo que cuidarme por lo que digo. Eso es importante porque puedo ser lo suficientemente honesta, porque hay un entorno que es un benigno y cuidadoso de quien soy. Cuando vos me preguntás por mi biografía. Una de las cosas que aprendí el año pasado, mientras estaba en tratamiento, fue que mis bisabuelos habían sido profesores 
en el siglo XIX. Ambos eran profesores de música. Tenía curiosidades por que me contaran cosas de mi familia... a veces tengo intuiciones y sensaciones que tienen que ver con mi pasado. Pero no como pasado de esta vida. Siento como si estuvieran escritos en mi piel quienes me precedieron y cada vez le encuentro más sentido a eso. No veo tan clara la diferencia entre el pasado y el presente; también ahí veo una continuidad. Siento que vivo una vida que puede ser mía, pero vivo cosas que son más viejas que yo. Como si se volvieran a enhebrar en mi vida, y también en la de mis hijos, cosas del pasado. Me siento desatando los mismos nudos que ellos quisieron desatar.

Hasta el año pasado yo sabía muy poco de mi abuela y en esta historia ella es el personaje fuerte. Mi abuela -mamá de mi mamá — era directora de escuelas. Pero no de cualquier escuela; era directora de una Casa del Niño en Mar del Plata. En la Casa del Niño en la que trabajaba se daba una contención complementaria a la escolaridad; entonces los chicos iban a la mañana a la escuela y a la tarde a esta Casa (o al revés, a la mañana a la Casa y a la tarde a la escuela). En la Casa del Niño se les hacía de comer, se hacía la tarea con ellos, se les sacaban los piojos. Y yo un poco me crié como un sujeto de estos lugares. También mi mamá después trabajó en una Casa del Niño que estaba por la zona del puerto, y ese espacio formó parte de mi crianza. Nosotros íbamos a trabajar con mi mamá, así que yo viví las jarras de té y el pan con mermelada. Pero, bueno, la figura fuerte, vuelvo a decir, ha sido mi abuela. Mi abuela es una presencia fuerte aún hoy. Era poeta y tenía mucha inquietud intelectual. Era muy lúcida y tenía un sentido político que no termino de descifrar; hablando con mi mamá o mi hermano me recuerdan su condición aguerrida y sus interesantes convicciones políticas. De hecho yo he llegado a sentir que tal vez para ella casarse o tener una familia puede haber sido como un desvío necesario. Otra cosa que recuerdo de mi abuela era que se encerraba a llorar; sobre todo le producía mucho dolor la desaparición de mi primo. Mi primo, su nieto mayor, es un desaparecido ${ }^{3}$ y eso a ella la golpeó mucho. Quizás por eso en todos los años en que yo viví cerca de ella nunca le escuché decir nada. Nunca le escuché una opinión política. Tal vez tenga que ver con que cuando yo era chica aún era un

\footnotetext{
${ }^{3}$ Durante la última Dictadura Militar en Argentina (1976-1983) individuos de la sociedad civil eran detenidos clandestinamente, torturados y en la mayoría de los casos asesinados sin que sus familiares o conocidos dispusieran de información respecto de su paradero. Es así que se usa el término "desaparecidos" para referirse a ellos.
} 


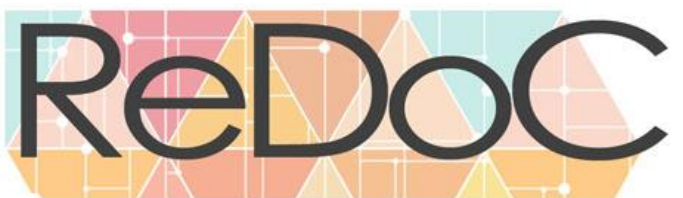

\section{Revista Docência e Cibercultura}

momento de mucho silencio; yo me acuerdo del miedo que se sentía cuando uno escuchaba a los militares en la cadena nacional y creo que mi abuela se adormeció en esa época. La abuela que yo conocí era una ama de casa que andaba siempre con un batón, pero me cuentan otras cosas de ella. Su mamá y su papá eran profesores de música, por eso casi diría que no le esquivé a nada. Quizás a medida que crece Sofía mi hija mayor-yo reencuentro ese germen político de mujer. Y además de mujer sensible a las realidades sociales a partir del desafío de la educación. Por eso a veces creo que eso no es mío; me llegó de otra gente. Pienso que como profesora de inglés lo tenía medio acallado y después estuve esperando el momento para salir.

Esa es mi sensación hoy, una historia que también es de mi familia, en la que se vino tejiendo a la educación como una utopía social. No soy la primera de mi familia, de eso estoy segurísima. De hecho mi primo que desapareció cuando tenía veinte años estudiaba medicina en La Plata y trabajaba para una organización educativa popular con chicos. Él también hacía pedagogía y justicia social, a su manera. Y creo que eso nos calló un poco. En mi familia fui la que empezó a hablar de vuelta, porque fui la pudo hacerlo. Mi tía militó desde la desaparición de su hijo en Madres de Plaza de Mayo, pero estuvo mucho tiempo callada y nunca habló de la historia de su hijo hasta hace muy poco. Y yo retomo mi lugar en la pedagogía desde ahí, una vez que pasó el peligro inminente - de que si hablamos nos desaparecen-yo vengo a soplar un antorcha que no estaba apagada. Hay algo ahí que me convoca.

\section{P3: Recuperás esta condición de pedagoga, inscripta en tu cercanía, desde esa} vocación que te convoca en tu familia pero ¿cuándo te reconociste como pedagoga? R3: Yo creo que ese germen político se despertó cuando comencé a leer sobre las pedagogías descoloniales. También creo que bajé unos escolanes en las jerarquías sociales cuando me reconocí como pedagoga. Cuando decía "soy profesora de inglés" todo el mundo decía “¿Qué bien!”. Y ahora - a veces a propósito-cuando digo pedagoga, muchos se quedan mirándome sin saber qué hacer. Porque la pedagogía tiene una identidad denostada, y eso es un lugar de lucha. Creo que lo que hacemos muchas veces es servirnos de las palancas que ya tenemos, siendo profesores universitarios o doctores, para palanquear a la pedagogía. 


\section{P4: ¿Qué es la pedagogía para vos?}

R4: Yo creo que la pedagogía es una narrativa sobre la relación educativa en la sociedad y esa relación educativa es constitutiva del ser humano, porque el ser humano es un ser social. Somos seres sociales y en nuestra relación es fundante la relación educativa, porque el ser no vive solo y una de las cosas que suceden en relación es la educación. Y esto no quiere decir, por supuesto, que crea que la dirección de lo educativo sea ni de los grandes a los chicos, ni del que sabe al que no sabe, sino que todas nuestras relaciones son educativas. Siempre que haya personas viviendo juntas hay relaciones educativas entre ellas. La comunicación es una parte de esta relación, pero la educación también implica todos los valores y todo lo que uno cree que debe ser, que no está incluido explícitamente en la comunicación. Cualquier cosa que tenga que ver con nuestra relación y que involucre todo eso, es una relación pedagógica. Porque además, siempre estamos necesitando, afirmándonos para que nos acepten. Creo que vivimos construyéndonos subjetivamente permanentemente y pidiéndole al mundo que nos acepte y eso es un acto educativo, porque trata de interpelar al otro. Es retórico; siempre estoy necesitando del otro. Todos necesitamos ser reconocidos y eso gesta una relación educativa. Hay una voluntad por que el otro acepte el conocimiento que nosotros producimos, y siempre producimos conocimientos sobre nosotros y sobre los demás.

Me fascina repensar la pedagogía como esa relación entre las personas. Tal vez lo que me fascina es pensar esa relación cuando es inspiradora de espacios de libertad. Cuando posibilita, cuando no es cercenarte y cuando no daña. Entonces para mí la pedagogía es la narrativa que habla de esa relación educativa, que es fundante de quienes somos y de lo que podemos ser. Tal vez la pedagogía sí sea una narrativa, en el sentido que todo el dominio de la vida social está colmado de prácticas sociales que a veces están verbalizadas y a veces no. La pedagogía suele ser explícita y verbal. La pedagogía es texto... lo otro sería la relación educativa en sí. Más bien diría que la pedagogía sería el esfuerzo por poner en palabras la relación educativa. La pedagogía es una relación. Me quiero correr de la pedagogía como disciplina, porque ese saber que se presenta como disciplina está cercenado y se presenta cercenante. Pero es importante porque la 


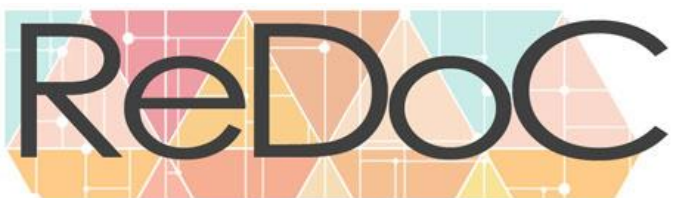

\section{Revista Docência e Cibercultura}

educación empieza a ser explicitada ahí. La práctica y la política son atributos de esa narrativa, o formas de manifestarla, o de su materialización.

\section{P5: Si comprendemos a la pedagogía más allá de su constitución disciplinar como} una narrativa vital sobre cómo nos educamos y sobre cómo nos relacionamos los humanos ¿cuándo y dónde comienza a explicitarse?

R5: Yo creo que la pedagogía es casi tan vieja como la educación y la educación, al ser una relación social fundante de la sociedad, es, en mi opinión, tan vieja como somos los seres humanos. La pedagogía debe haber surgido con ese primer relato, con esa primera narrativa de cómo debe ser la educación y cómo debe se pensaba esa relación educativa. Entonces yo entiendo que la pedagogía es una ciencia vieja o más bien una narrativa vieja, porque no es sólo una ciencia sino una narrativa nómade. Es una narrativa que tiene fuerza, una fuerza instituyente. En el siglo XIX se quiso instituir como una disciplina; tal vez al principio lo logró pero después frente al positivismo perdió parte de su rumbo.

Hay una discusión histórica en la educación de los pedagogos y de los profesores, en la separación de los institutos de formación docente de las universidades. Cuando las universidades empezaron a adoptar un modelo humboldtiano se empieza a despegar lo que es pedagogía y se la pasa a los niveles inferiores de la enseñanza. Detrás de esto, o no tan detrás, se entiende a la formación para ser profesor como académica o disciplinar más que pedagógica (y con un sentido estrecho de didáctica en todo caso). Es decir que para ser profesor tenés que saber tu disciplina y a lo sumo tenés que conocer tres o cuatro recetas para saber enseñarla. Eso todavía perdura y tiene consecuencias crueles, porque se obturó una posibilidad de desarrollo de un sentido pedagógico en la formación universitaria. Creo que en gran parte esto sucedió porque el positivismo no supo lidiar con lo pedagógico y lo que hizo fue desplazar el prestigio social desde la pedagogía a las ciencias de la educación. Como se la tildó de espiritualista porque lidiaba con cuestiones que no eran científicas, observables o medibles, sino más bien filosóficas, se la desterró.

La pedagogía como campo de saber tiene una condición filosófica, del por qué, el para qué, del qué sucede en sentido político, y una serie de dimensiones que no son 


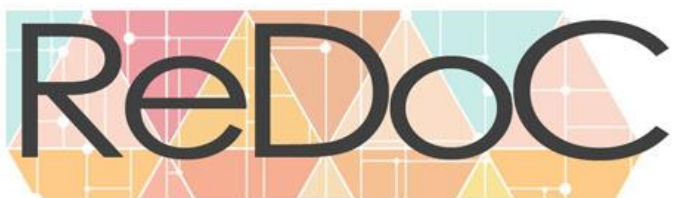

\section{Revista Docência e Cibercultura}

observables, documentables o medibles. Las ciencias de la educación se presentan como una parte de la historia, una parte de la filosofía, una parte de la sociología, etc. que se ocupa de la educación, pero que no tienen como preocupación central a la educación. Muchas veces pareciera que las ciencias de la educación miran a la educación de costado. Mi sentir es que nosotros necesitamos de la pedagogía como una narrativa que se ocupe de primera mano de la educación. No como una cuestión secundaria. Porque es una cuestión primordial en la sociedad. Diría que la pedagogía se tiene que indisciplinar para construir algo que gire alrededor de la educación, pero necesitamos para ella una narrativa que le sea propia. Que no sea una disciplina científica, sino un corpus de relatos o corpus de conocimientos que van mutando para dar explicaciones contingentes y provisorias de lo que va sucediendo con las relaciones educativas.

\section{P6: Entonces ¿la educación necesitaría más de la pedagogía?}

R6: Pienso que sí, que la pedagogía puede ofrecer un camino y no, por ejemplo, sólo la didáctica. Recientemente en un seminario de posgrado lo que intenté hacer fue mostrar por qué la didáctica de la educación superior suele reproducir un lugar anquilosado de lo pedagógico. Yo creo que la didáctica del nivel superior, que ha sido muy influyente en nuestra comunidad académica en Mar del Plata y en otras partes del país, a pesar de la buenas intenciones de Alicia Camillioni, Edith Litwin y tanta otras, es un saber cercenante que está muy cooptado por las jerarquías y relaciones coloniales del saber, sobre todo por la división entre investigación y enseñanza. Por ejemplo Gary Fenstermacher, que es uno de los autores que más ha trabajado en la "buena enseñanza”, define muy claramente esa división entre investigación y enseñanza. Él dice que el que hace investigación no es el que enseña. Entonces alguien produce investigación y el otro es un ejecutor. Por eso yo creo que uno si uno analiza lo que fue la "Nueva Agenda de la Didáctica" en Argentina, allí hay mucho de psicología cognitiva, mucho de la didáctica disciplinar y mucho de las jerarquías del nivel superior respecto de otros niveles de enseñanza, pero poco de pedagogía. Para mí esa mirada de la didáctica enajena la posibilidad de hacer de la educación un relato político y de la pedagogía un relato con capital político. 


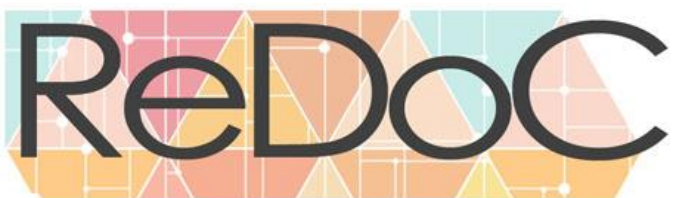

\section{Revista Docência e Cibercultura}

Yo creo que la pedagogía podría ser el relato de las relaciones educativas que tenemos, que necesariamente va mutado. Y que como es un relato (es un gran relato, como lo es la medicina también) podría servirnos para generarnos algunas autorizaciones. Para dar lugar a otras prácticas. Me parece que todos los grandes relatos pueden hacer lugar para que entren cuestiones que puedan ser socialmente autorizadas. Porque están investidos de poder social y son lugares interesantes para que se escuchen otras cosas.

Sí quiero una pedagogía fuerte. Cuando digo pedagogía, hablo de una narrativa. Y una narrativa, interpelada y porosa, que vaya cambiando. Que sea una para mí, otra para vos y otra para el señor que ahora está cruzando la calle. Y está bien que así sea, porque cada uno necesita algo distinto de la pedagogía. O sea, quiero una pedagogía sin unicidad y sin monoglosia. Una narrativa que se ocupe de lo educativo en la sociedad, que se pregunte sobre qué relaciones de poder establecemos a través de la educación, sobre cómo trabajamos la autoridad, sobre cómo usamos la palabra para definirnos y definir al otro, hasta también cómo la desmantelamos a ella misma. No creo que con la pedagogía vayamos a acabar con la injusticia social, porque no es la única forma de combatirla, pero sí creo que es un lugar todavía importante y estructurante de los vínculos sociales. Me parece que se puede entrar a la justicia social desde cualquier lado y nosotros lo hacemos por acá. Pero si la pedagogía tiene hilos tan fuertes que te cortan va a ser difícil; creo que hay que ir aflojando la trama para que sea una narrativa más habitable y amable con la vida.

\section{P7: ¿Qué lugar ocupan la escuela y la universidad en la pedagogía?}

R7: La instituciones sociales son ámbitos densos. La idea de densidad, que me llega un poco del yoga y otro poco del nuevo materialismo o el nuevo empirismo, nos dice que lo único que hay son aconteceres. Sólo existen movimientos, y los sentidos que construimos a partir de ellos vendrían a ser un segundo orden. Porque lo que en realidad uno hace es vivir. Uno ríe, llora, va, viene, sufre, goza, se mueve, está viviendo. Este nuevo materialismo nos viene a mostrar cómo salvo vivir, el resto es una ficción. Es algo impuesto. Al problematizar ello y encontrarle sentido, lo que vamos construyendo son una especie de nidos, que son los significados que nosotros le otorgamos al vivir. 
¿Qué es la estabilidad? La estabilidad es ficticia. Lo que es frecuente es el movimiento, la inefabilidad, la impermanencia. Pero eso sí, necesitamos sentido. Porque los sentidos nos dan anclaje. Pienso que los sentidos son como una gran necesidad humana y también una cualidad a abrazar, ya que también allí podemos crear algo maravilloso y crear belleza. Nuestra condición de humanidad no es un signo de debilidad; es nuestro potencial poético. Lo bueno es lo malo. Creo es que esos sentidos son pequeñas densidades; el problema es cuando empezamos a dar a eso más poder o más atención que a la vida misma. Pero eso tiene que ver con el apego; si nosotros pudiéramos aceptar la vida como es y como ella transita, todo sería más fácil. También iríamos deviniendo, en lugares a donde llegaríamos, que irían sucediéndose.

Lo que pasa es que hay algo nuestro, que también es humano, que hace que empecemos a concentrar poderes en esos lugares sociales. Y después es muy difícil sacarles importancia, porque esos poderes te contienen y te abrigan. Para mí te incautan. Me parece que hay que ser más nómade para ser más feliz, que lo nuestro es ser nómade. Pero todavía no encontramos la forma de fluir sin agarrarnos tan fuerte. Yo no me deshice de mis miedos para dejarme llevar por el pulso de los días. Pienso que los miedos también son mojones que pongo en el agua para que no circule tan rápido todo y para que no se vaya. Y las instituciones sociales, todas, la familia y las que vamos inventándonos en cada época, son los bastiones de esos mojones en el agua que hacemos entre todos. Y parecería, también, que todos los necesitamos. Como en la tesis de la transmisión interrumpida de Hassum: todos necesitamos transmitir algo de valor y todos necesitamos romperlo y recrearlo. Es necesario construir y también es necesario romper y reconstruir. Como los castillos en la arena, que uno hace y después viene el mar y se los lleva. Y a pesar de eso, uno vuelve a construir otro. Es decir, el mar se lo lleva pero está en mí -en nosotros-construirlos. Porque en esa construcción está el sentido y la belleza que le ponemos a nuestra vida. Es lo único que venimos a hacer aquí, a dotar de sentidos a las cosas y a ponerles el cuerpo para que nos atraviesen otras nuevas. Los humanos nos parecemos en eso de encontrar sentidos. Las instituciones sociales se anquilosan y son conservadoras. El rol de la institución no es dejar que todo fluya, es dar la permanencia y la quietud. La escuela está preparada para eso. Pero eso también es necesario, ¿no? Es necesario que alguien ponga una estaca en algún lugar. 
Pero esa estaca se debería levantar e ir mudando. Por eso es importante preservar este espíritu nómade, uno podría ir deviniendo nómada.

En la educación tiene que haber un punto de coerción. Es indispensable que así sea pero no tiene nada de absoluto, porque es arbitrario. Recuperar la pedagogía es para nosotros parte de un juego. Nosotros jugamos al juego del universitario. Ese juego tiene unas condiciones, que es que si el estudiante va a aprobar vos tenés que demostrar que ese estudiante puede dar una respuesta significativamente diferente al final que al principio del proceso que acompañaste. ¿Quién exige eso? el juego de la universidad. Ahora pensar que eso es la forma correcta es otra cosa. Yo creo que eso tiene que ver con lo que vos negociás con tu entorno.

Respecto a lo que hacemos en la universidad, yo creo que lo importante, más que aprender, es reconocer si les pasó algo a los estudiantes y si nos pasó algo a nosotros. No sé si exista un conocimiento por el que valga la pena inmolarse; más bien es importante eso que les pasa y nos pasó. No pondría las manos en el fuego por nada de lo que enseñamos, pero sí me parece importante que uno establezca modos justamente posibles del juego que estamos jugando. Somos profesores en una universidad y tenemos que poner unas condiciones, que sean lo menos irrespetuosas posibles de lo que creemos. Pero no nos podemos poner en un lugar de decir que lo que hacemos está bien; lo que hacemos no se contradice tanto con lo que pensamos, pero sigue siendo un juego. Socialmente uno tiene que jugar y hay algo de materialidad en todo eso. Por eso yo creo que en la universidad vale la pena inmolarse para que a los estudiantes y a nosotros los docentes nos pase algo. Sin embargo que les y nos pase algo hoy es difícil, porque el sistema educativo está muy desafectado.

\section{P8: Por eso es importante restaurar las afectaciones en la educación...}

R8: Si, claro. Pero yo también creo que ahí hay una ficción. Una ficción moderna sobre la posibilidad de que uno puede hacer pensamiento sin cuerpo o pensamiento sin emociones. En nuestro caso que investigamos sobre esos temas, todos los autores que vamos consultando justamente nos dan argumentos racionales para ir quitándole autoridad a esa ficción racional de la academia. Que por más que ya no tenga autoridad, y que ya nadie la pueda defender, aún tiene mucha vitalidad y mucho arraigo. Nosotros 
actuamos como si el conocimiento fuera algo que estuviera en nuestra cabeza. Y las neurociencias, por ejemplo, sólo refuerzan estas ideas. Yo creo que si vos no te afectás o si no estás afectado por las cosas, ¿cómo podrías hacer algo por vos?, ¿cómo podrías hacer algo por otras personas? Entonces la educación es la belleza, el arte, la sensibilidad, las emociones, el cuerpo, o todo eso que nos afecta. A mí me parece que no es posible conectarse con el otro si vos no te conectás con tus afectos y con eso que te afecta.

Yo creo que nosotros somos cuerpos pulsantes y que estamos deserotizados por un programa histórico, pero hoy nos corresponde la reerotización. Porque sólo así vamos a restituirnos. Es como si estuviéramos lisiados. Y al estar lisiados, estamos desafectados el uno del otro. Me parece que necesitamos reconocernos más sensibles frente al otro, sobre todo porque cuando podés ver al otro te podés ver a vos. Para mí la pulsión política es una pulsión sensible, el afecto es político. No es el afecto romántico, el "yo te quiero". Yo te diría que la estética y la belleza son afectos. Porque son algo que nos afecta. O el amor, pero no el amor de pareja -que suele no ser siempre-sino esa sensibilidad de estar con otra persona y sentir amor. Como cuando estás con alguien y de repente sentís un profundo e incompresible sentimiento, a pesar de ser la primera vez que lo vez. Yo creo que hay algo muy noble ligado a los afectos. Algo que se siente bien adentro. Algo que estás vibrando, como una música que te puede hacer bien. Pero lo que no entiendo es por qué nos apartamos de eso. Aunque entiendo que el tipo de vida que llevamos -que requiere el mundo de la modernidad capitalista- necesita que nos enajenemos de nosotros mismos.

\section{P9: ¿Y podríamos pensar lo mismo con el sexo?}

R9: Absolutamente. Por ejemplo, conozco muchas mujeres de mi edad que no tienen deseo sexual. Yo creo que si hay un signo de que vos no estás conectado con vos es ese. Si no te pasa eso, estás medio muerto. Estas necrosado, ese necrosado que vos decías. Creo que estamos muy mal en eso. Que entendemos muy mal el sexo, ligado a una cierta violencia sobre el otro, en vez de entenderlo como una cuestión o como una elevación de lo espiritual. Pienso que estamos mal educados y que estamos a años luz de educarnos bien. Porque la escuela lejos está de eso y la sexualidad es una búsqueda 
personal, en la que cada uno se las arregla como puede. Lo que no quita decir que después uno encuentre compañeros que nos puedan ayudar. A veces siento que es siniestro, porque nos estamos apartando de aquello que nos hace creativos, nos hace pujantes y nos hace palpitar la vida. Es tremendo vivir en un mundo sin desear, sin desearlo todo. Sin que todo te sea apetecible y gustoso; nos hace estar como si estuviéramos secos. Tal vez el tiempo nuestro sea el tiempo de despertarnos. Tal vez cada tiempo tenga algo, como una pequeña misión de rescate, y la nuestra hoy venga por estos lugares. Hay veces que pienso "pasó toda esta semana y no estuve conmigo y siento que perdí el hilo” ¿Quién es esta persona? que se levanta, que hace la comida, que va al supermercado, que cuida a los chicos, que va a dar clases, que se sienta a escribir. Y pienso en que no se encontró, porque parecería que todo está preparado para eso. Y quizás este sea un rescate que ya no tiene tanto que ver con la colonización, pero creo me gusta pensar que la pedagogía descolonial, con cruces cosmogónicos y prácticas ancestrales, nos muestra que todo, todo, todo -absolutamente todo-podría ser de otro modo. Entonces se deshace la diferencia entre lo divino, lo místico, la religión, la tierra, el ser. Yo estoy empezando a pensar que no hay nada que yo no sea, que yo no soy diferente de un árbol o de un águila. Tampoco sé por qué es la pedagogía descolonial la que me da tanto libreto, ya que estas cosas se van un poco de su agenda.

\section{P10: ¿Qué sería una pedagogía descolonial?}

R10: Para mí la pedagogía descolonial es una práctica, primero. No, unas prácticas. Son unas prácticas que tratan de no moverse lejos, que no aspiran a ir por todo. Tienen sentido ante un inquietud local, personal, situada y son respetuosas de la historia. Y acá también se nos juntan los planos — cuando yo te digo que son respetuosas de la historia y te empiezo a hablar de mis antepasados. Yo soy mi familia. Yo soy toda mi familia y ese momento en la historia es toda la historia también. Y de eso no hay que renegar. Cuando uno antes ame a sus padres, seguramente se sentirá más libre. Y cuando digo los padres, me refiero a todo lo legado. Yo vivo en un momento, pero hay algo que me viene legado. Vivo en Mar del Plata y soy descendiente de lo que se llama europeos -y también de árabes - y a veces me confundo y creo que no soy de esta tierra. Pero yo me fijo en esta tierra y en la historia de esta tierra, que no es la historia de los europeos que 


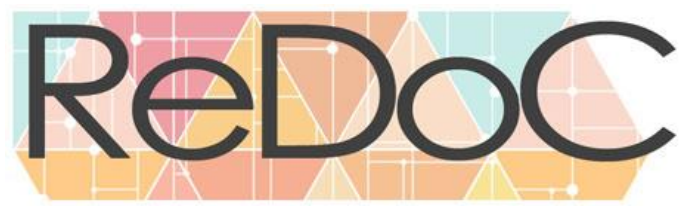

\section{Revista Docência e Cibercultura}

vinieron y nada más. También es de lo que estaban y el dolor de cómo fueron tratados. Todas esas marcas también están acá y en este contexto de Mar del Plata. De hecho uno sólo puede entender Mar del Plata si entiende que hubo un desierto que no era desierto, que hubo una laguna antes de ser una Laguna de los Padres.

Para mí la distinción entre yo y el resto es una distinción ficticia. Si vos mirás la piel de una persona microscópicamente no hay un límite. Hay un momento en que lo que es piel y lo que no es piel se con-funde. Vos tenés en tu sangre y en tu cuerpo nitrógeno que ha estado en miles de lugares antes. Lo que somos es una composición; realmente nos habita la historia, nos habitan los otros. Pero a la vez hay algo que es mío, que es este sentido que le doy. Como un pedacito. No sé, es una cuestión rara. Esta todo, pero también está el nudito. Y el nudito soy yo, quien le pone sentido a la cosa. Yo entiendo el relato de mi vida como único y a la vez de todos. ¿Cómo saber de qué maneras interesantes el aire que estoy respirando ahora dialoga con los químicos que tengo en mi cuerpo? Uno piensa que la piel es una cosa que te aísla, pero no es más que una autopista. Son caminos y medios de contacto. No estamos aislados en ningún sentido, no sé cómo se come eso en la pedagogía. Pero para mí una pedagogía descolonial es un relato, que tiene memoria, que desarma, que suaviza estas redes de significados que sostienen la vida, que las hacen más laxas, menos absolutas y menos enteras. No es lo que Aníbal Quijano dice que es, lo que Catherine Walsh dice que es, ni lo que yo dije que era hace dos minutos. Es un nombre que a mí me resulta generoso, porque contiene mucho. Yo las entiendo como tecnologías generosas, abiertas, amplias, porosas. Como una narrativa de lo que no pudo hacer la posmodernidad, en ese casi imposible pensarse sin estructuras. Pero acá las estructuras pueden fluir, pueden invertirse y pueden desarmarse. Yo la entiendo como un espacio de libertad, como un espacio de libertad para tomarme y para generar espacios de libertad para que otros se tomen.

P11: ¡Qué hermoso es escucharte! Para terminar la entrevista me gustaría retomar esta idea de las pedagogías descoloniales como prácticas de autorización discursiva para pensar la descomposición del campo disciplinar y preguntarte ¿qué nos toca hacer como pedagogos y como (des)compositores de la pedagogía? 


\section{Revista Docência e Cibercultura}

R11: En otras oportunidades te escuché atentamente y creo que la idea de descomposición es inspiradora. Tal vez la clave sea la alteridad continua entre componer y descomponer, como un acto cotidiano, natural y nuestro. Como la planta que se cae y abona el terreno. En esa fluidez, no entendería nunca la una sin la otra. Una lleva necesariamente a la otra. Hoy diría que lo bueno es no cristalizarse, ya que todo está en movimiento. Aunque a veces es intranquilizador vivir en el fluir y queremos interrumpir y decir "es esto" y quedarnos tranquilos. Todo esto tiene que ver con dejar de pensar que podemos crear una verdad. La idea de creatividad no implica que yo, María Marta, puedo producir algo nuevo; cuando hablo tal vez diga algo que parece novedoso pero está sobre la base de lo dicho y lo creado. La palabra composición además le devuelve su estatus de arbitrariedad y de reconocer que ninguno de nosotros va a decir la verdad. Siempre estoy inventando algo pero está en un tiempo y en un espacio; es importante reconocer esto para no creérmela. Diría que la narrativa no puede llegar a investirse de verdad verdadera, se inviste de verdad convencional. Me fascina tratar de recordarnos permanentemente que las narrativas no son la verdad. Eso sí, pueden ser una síntesis conveniente útil o seductora, pero no son la verdad. Componer y descomponer tiene que ver con acordarte que sigue siendo mágico, algo que se conjura y que nunca tiene una verdad que trasciende un tiempo y un espacio. Además uno puede ser un compositor o ser un intérprete (como los relatores y los narradores, o como aquellos que crean historias y los que simplemente las reproducen). El relator se cree no narrador, pero es imposible no ser narrador. Yo diría que se esconde. En la escuela o en la universidad, en el juego de lo escolarizado, todos docentes y estudiantes- nos hacemos un poco relatores. Pero si uno deja de jugar ese juego, reconocemos que toda persona narra y crea, que toda persona deviene movimiento y descomposición. 


\section{Referencias}

Ribero, T Sanches, C e Ferreira, R (2018). “É possível a conversa como metodologia de pesquisa?" In su: Conversa como metodologia de pesquisa: por que não?. Rio de Janeiro, Editora Ayvu.

Yedaide, MM (2016) El relato oficial y los otros relatos sobre la enseñanza en la formación del profesorado, Facultad de Humanidades-UNMdP. Tesis de Doctorado en Humanidades y Artes. Rosario, Universidad Nacional de Rosario. 